\title{
Corpus Analysis of Interactional Response Words as Indicators of Shared Understanding in Medical Problem- Based Learning Tutorials
}

Olukayode Matthew Tokode ( $\sim$ olukayodetok@yahoo.com )

University of Nottingham Medical School

Reg Dennick

University of Nottingham Medical School

Research Article

Keywords: shared understanding, shared knowledge, corpus linguistics, Wmatrix 3, problem-based learning, medical education

Posted Date: September 8th, 2021

DOI: https://doi.org/10.21203/rs.3.rs-812492/v1

License: (9) (i) This work is licensed under a Creative Commons Attribution 4.0 International License. Read Full License 


\section{Abstract}

\section{Background}

Shared understanding is essential to effective collaborative learning. Interactive processes occurring in problembased learning (PBL) tutorials have been explored to determine their cognitive and social advantages, but shared understanding is a relatively under-researched social process of PBL. The objective of this study is to describe how medical students share understanding in medical problem-based learning tutorials.

\section{Methods}

We recruited participants from first-year medical students in a single institution's problem-based learning graduate entry curriculum. Transcripts from full cycles of eight tutorial groups were compiled to form the study corpus. Small interactional response words as indicators of shared understanding were measured using the Wmatrix 3 programme, and concordance lineswere analysed manually to determine word functions.

\section{Results}

Interactional response words were most prevalent in session 1 and least prevalent in session 2 of the PBL cycle. Interactional response words were used to mark unexpanded and simple and complex content expansion functions. While affirmation content expansion functions and reactive content expansion functions were more prevalent in sessions 1 and 3 , negation content expansion functions were more frequent in session2. The frequency of interactional response words and their functions seem to align with the focus of each PBL tutorial session.

\section{Conclusions}

Demonstrating the feasibility of corpus linguistics methodology for PBL concept analysis, this study showed that students in PBL tutorials attained sophisticated levels of shared understanding. We discussed the implication of the results for interprofessional teamworking and patient-doctor communication.

\section{Introduction}

Research on problem-based learning $(\mathrm{PBL})$ curricula has evolved into microgenetic analyses of why and how PBL works [1]. Process-focused research has studied several aspects of PBL processes including learning issue generation [2], knowledge construction [3, 4], biomedical reasoning [5], and conceptual change [6, 7]. Shared understanding processes in PBL tutorial conversation (talk) have been insufficiently studied, even though students collaborate in PBL tutorials [8] and shared understanding is essential to collaboration [9]. These processes result in shared understanding marked by evidence of conceptual convergence such as moving to the next topic, simple affirmative acknowledgement or recitation, and mutual elaboration or concept completion [10].

The technologies so far applied to talk analysis do not profile verbal data into grammatical categories, and conducting an analytic process is difficult [11]. The Wmatrix 3 software has proved useful for measuring linguistic categories for further manual analysis [12]. We applied corpus linguistic methodology to analyse graduate entry medical students' shared understandings during PBL tutorial talk. We used Wmatrix 3 to measure small interactional response words as indicators of shared understanding to answer the following questions: 
1. What is the frequency of common interactional response words in PBL tutorial transcripts?

2. What are the common functions of small interactional response words in PBL tutorial transcripts?

3. What level of shared understanding is evident in PBL tutorial conversation?

4. How is the evidence of shared understanding related to PBL discourse content across tutorial sessions?

\section{Shared understanding}

All knowledge is bound up in social, cultural, and physical activity [13]. Academic talk has been viewed as display, confirmation, and repair of knowledge within active situations [10]. Shared understanding refers to overlapping understandings among group members brought about through collaborative negotiation and acceptance of individual contributions [14]. Shared meaning is a group achievement attained when discourse participants engage in collaborative social activity [15]. Shared understanding involves refining ambiguity and partial meanings through cycles of display, confirmation, clarification, questioning, and repairing of shared meaning [16]. The current emphasis on interprofessional teamwork [17] and patient-doctor shared decision-making [18] indicates that medical students need to learn understanding in addition to the acquisition of content knowledge [19].

\section{Methods}

\section{Study design}

Our previous study [12] demonstrated the suitability of corpus methodology for the analysis of transcripts of PBL tutorial discussions more systematically and with less bias. The present study extends the application of the corpus analysis methodology to an analysis of PBL talk to assess evidence of shared understanding.

\section{Setting}

Graduate entry PBL at the University of Nottingham Medical School in Derby is a hybrid curriculum. Students and facilitators meet for 4-5 hours weekly, divided into three sessions (PBL 1, 2, and 3). The first session concerns problem analysis and learning issue generation for self-study, with the results of the self-study being presented in the second session. Students then devise a management plan and reflect on a specific case in the third session.

\section{Participants}

Participant recruitment occurred through the provision of verbal and written information. We invited the 2009 and 2010 student cohorts to participate in the study. Participation was voluntary. Of the twelve tutorial groups in each cohort, six of the 2009 cohort and five from the 2010 cohort participated in the research. Inclusion criteria were willingness to participate in the research and completion of consent forms for audio and video recordings. Exclusion criteria were unwillingness to participate in the study, refusal to consent to audio and/or video recording, and being a temporary facilitator. Recruitment into the study took place after the students had acquired three months' experience with the PBL curriculum.

\section{Data collection}

The student's audio- and video-recorded the tutorial discussions using an Olympus DS-2500 dictation machine and a Sony HD camcorder, respectively. An external professional transcriber transcribed the audio recordings 
verbatim.

\section{Corpus formation}

We removed irrelevant conversation from the transcripts. The first author used video footage to assign transcript statements to the tutorial participants. Unique codes were assigned to the participants for identification.

The study corpus consisted of transcripts from eight tutorial groups. Of the eleven consenting groups, transcripts from three groups were excluded because of poor transcriptions due to inaudibility, and multiple incomplete recording because of equipment failure. Transcripts were compiled by PBL session. The students' contributions formed the students' file, and the whole corpus file contained the contributions of the students and the facilitators. The transcript files were converted to plain text files and uploaded to the Wmatrix 3 online software. The students' file was used for measuring the interactional word frequency, while the whole corpus file was used for concordance analysis. The study corpus consisted of 253,145 words: PBL $1=86,414, \mathrm{PBL} 2=108,655$, and PBL 3 $=58,076$. Further information on Wmatrix 3 is available on the University of Lancaster's website (http://ucrel.lancs.ac.uk/wmatrix3.html).

\section{Small interactional response words to measure shared meaning}

The following small interactional response words have been considered to mark shared meaning during interactional conversation [20]:

1. Acknowledgement responses such as continuers (e.g., 'uh', 'yeah')

2. Assessment tokens (e.g., 'gosh', 'really')

3. Repair tokens (e.g., 'I mean')

4. Attention check tokens (e.g., 'you know')

5. Agreement tokens (e.g., 'that's right', 'exactly', 'I see')

6. Appreciation (e.g., 'thank you', 'well done')

7. Negation tokens (e.g., 'No').

This study adopted these response words in its analysis.

\section{Data analysis}

The Wmatrix 3 programme was used to retrieve the interactional response words from the interjection (UH) partsof-speech category. The five most frequently used words were retrieved, further inspected, and analysed. Concordance lines were exported to an Excel spreadsheet file. Manual analysis was done to disambiguate, remove repeated words, and determine the functions and evidence levels of the interactional words. The raw and normalised frequencies of the words were then calculated. Coding of the word functions followed a directed content analysis procedure [21].

\section{Statistical analysis}

The Log-Likelihood calculator (http://ucrel.lancs.ac.uk/llwizard.html) was used to calculate the normalised frequency (per 100 tokens) and normalised frequency comparison. A p-value of less than 0.05 and a LogLikelihood (LL) value greater than 3.84 were considered significant. 


\section{Frequency of interactional response words}

There were 4,213 words in the five most frequently used small interactional responses in the whole corpus, as follows: non-lexical affirmation word 'yeah', 1,722 (40.87\%); lexical affirmation word 'yes', 1,164 (27.63\%); negation lexical word 'No', 1,002 (23.78\%); and reactive word 'Oh'/'Ah', 325 (7.72\%).

Overall, the students used more than 1.0 interactional word per 100 tokens to mark their discourse across PBL sessions, but the interactional words were less frequent in PBL 2 (1.40 per 100 tokens) than in either PBL 1 (1.96 per 100 tokens) or PBL 3 (1.79 per 100 tokens). Participants used more than 1.0 affirmation word ('yeah/yes') per 100 tokens in PBL 1 and PBL 3 (1.35 and 1.21 per 100 tokens, respectively), but less than 1.0 per 100 tokens in PBL 2 (0.94 per 100 tokens). The variation of affirmation words across the PBL sessions was statistically significant (Table 1 below).

Table 1

Identifying shared understanding: Raw and normalised frequencies per 100 tokens of occurrence of the five principal small interaction response tokens indicating shared understanding and their log-likelihood values in each problem-based learning session

\begin{tabular}{|c|c|c|c|c|c|c|c|c|c|c|c|}
\hline \multirow[t]{3}{*}{ Word } & \multicolumn{6}{|c|}{ Interactional response words } & \multicolumn{3}{|c|}{ Log Likelihood (LL) value } & \multicolumn{2}{|c|}{$\begin{array}{l}\text { Combined PBL } \\
\text { groups }\end{array}$} \\
\hline & \multirow{2}{*}{\multicolumn{2}{|c|}{$\begin{array}{l}\text { PBL } 1 \\
\text { RF NF }\end{array}$}} & \multirow{2}{*}{\multicolumn{2}{|c|}{$\begin{array}{l}\text { PBL } 2 \\
\text { RF NF }\end{array}$}} & \multirow{2}{*}{\multicolumn{2}{|c|}{$\begin{array}{l}\text { PBL } 3 \\
\text { RF NF }\end{array}$}} & \multirow{2}{*}{$\begin{array}{l}\text { PBL } 1 \\
\text { vs PBL } \\
2\end{array}$} & \multirow{2}{*}{$\begin{array}{l}\text { PBL } 2 \\
\text { vs } \\
\text { PBL } 3\end{array}$} & \multirow{2}{*}{$\begin{array}{l}\text { PBL } 1 \\
\text { vs PBL } \\
\mathbf{3}\end{array}$} & \multirow[t]{2}{*}{ RF } & \multirow[t]{2}{*}{ NF } \\
\hline & & & & & & & & & & & \\
\hline Yeah/yes & 1169 & 1.35 & 1017 & 0.94 & 700 & 1.21 & $\stackrel{+}{73.99 *}$ & $\overline{26.04 *}$ & $+5.89 *$ & 2,886 & 1.14 \\
\hline No & 350 & 0.41 & 395 & 0.36 & 257 & 0.44 & $\begin{array}{l}+2.16 \\
\mathrm{NS}\end{array}$ & $\overline{5.93 *}$ & $\begin{array}{l}-1.16 \\
\text { NS }\end{array}$ & 1,002 & 0.40 \\
\hline Oh/Ah & 137 & 0.16 & 107 & 0.10 & 81 & 0.14 & $\stackrel{+}{13.76 *}$ & $\overline{5.47 *}$ & $\begin{array}{l}+0.84 \\
\text { NS }\end{array}$ & 325 & 0.13 \\
\hline Total & 1656 & 1.96 & 1519 & 1.40 & 1038 & 1.79 & $\stackrel{+}{90.95^{\star}}$ & $\overline{36.56 *}$ & $+5.57^{\star}$ & 4213 & 1.66 \\
\hline $\begin{array}{l}\text { The numb } \\
\text { Wmatrix } 3 \\
\text { significant } \\
\text { greater tha }\end{array}$ & $\begin{array}{l}\text { of sm } \\
\text { ag 'inte } \\
R F=\text { ra } \\
3.84 .\end{array}$ & interc & $\begin{array}{l}\text { tional } \\
\text { (UH) ; } \\
(U V \cdot)\end{array}$ & pons & $\begin{array}{l}\text { words in } \\
\text { lem-bas }\end{array}$ & dicatin & $\begin{array}{l}\text { shared } \\
\text { ing; } 1,2 \text {, }\end{array}$ & $\begin{array}{l}\text { derstan } \\
d 3=s e \\
\end{array}$ & ng was I & $\begin{array}{l}\text { asured } \\
\text { ind 3;; }\end{array}$ & $\begin{array}{l}\text { g the } \\
\text { not } \\
\text { to or }\end{array}$ \\
\hline
\end{tabular}

Although the students generally used fewer than 1.0 negation words per 100 tokens across the PBL sessions, the least prevalence was noted in PBL 2 ( 0.36 per 100 tokens). There was no significant difference in the negation frequency in PBL 1 and PBL 3 (0.41 vs 0.44 per 100 tokens, LL - 1.16). However, negative words were significantly overused in PBL 3 compared to PBL 2 ( 0.44 vs 0.36 per 100 tokens, $L L+5.93$ ). Likewise, fewer than 1.0 reactive words per 100 tokens were used across the PBL sessions, with reactive words having nearly the same prevalence in PBL 1 and in PBL 3 ( 0.16 vs 0.14 per 100 tokens, $L L+0.84$ ) but being least used in PBL 2 ( 0.10 per 100 tokens). The results suggest that PBL 1 was the most interactive session, and PBL 2 the least.

\section{Functions of small interactional response words}


The analysis of interactional response words showed various functions. However, due to limitations of space, only functions that occurred in tens or more in each tutorial session have been reported, as follows: 3,509 (83.29\%) of the total 4,213 words: PBL 1 = 1,387, PBL 2 = 1,288, and PBL $3=834$ (Table 2 below). 
Table 2

Patterns of shared understanding codes: Normalised frequencies per 100 tokens and Log Likelihood values for frequent expansions of small interactional response words indicating shared understanding

\begin{tabular}{|c|c|c|c|c|c|c|c|c|c|}
\hline \multirow[t]{2}{*}{ Word } & \multirow[t]{2}{*}{ Function } & \multicolumn{3}{|c|}{ NF per 100 words } & \multicolumn{3}{|c|}{ Log Likelihood (LL) } & \multicolumn{2}{|c|}{$\begin{array}{l}\text { All PBL } \\
\text { Combined }\end{array}$} \\
\hline & & PBL1 & PBL2 & PBL3 & $\begin{array}{l}\text { PBL1 } \\
\text { versus } \\
2\end{array}$ & $\begin{array}{l}\text { PBL2 } \\
\text { versus } \\
3\end{array}$ & $\begin{array}{l}\text { PBL1 } \\
\text { versus } \\
3\end{array}$ & RF & NF \\
\hline \multirow{12}{*}{$\begin{array}{l}\text { Affirmation } \\
\text { (Yeah/Yes) }\end{array}$} & Acknowledgement & 0.27 & 0.11 & 0.19 & $\begin{array}{l}+ \\
69.93 *\end{array}$ & $\overline{19.38 *}$ & $+8.50^{\star}$ & 456 & 0.10 \\
\hline & Talk sequence & 0.03 & 0.04 & 0.08 & $\begin{array}{l}-0.35 \\
N S\end{array}$ & $\overline{12.01 *}$ & $\overline{14.44^{\star}}$ & 118 & 0.05 \\
\hline & Agreement & 0.01 & 0.09 & 0.17 & $-\overline{61.25^{\star}}$ & $\overline{16.69 *}$ & $-\overline{113.58 *}$ & 210 & 0.08 \\
\hline & Confirming & 0.28 & 0.12 & 0.12 & $\begin{array}{l}+ \\
66.48^{*}\end{array}$ & $\begin{array}{l}-0.00 \\
\text { NS }\end{array}$ & $\begin{array}{l}+ \\
45.92^{*}\end{array}$ & 441 & 0.17 \\
\hline & Comment & 0.18 & 0.04 & 0.06 & $\begin{array}{l}+ \\
89.35^{\star}\end{array}$ & $\begin{array}{l}-1.42 \\
\text { NS }\end{array}$ & $\begin{array}{l}+ \\
45.49 \star\end{array}$ & 236 & 0.09 \\
\hline & Restate & 0.15 & 0.10 & 0.09 & $\stackrel{+}{10.19 *}$ & $\begin{array}{l}+0.09 \\
\text { NS }\end{array}$ & $+8.75^{\star}$ & 293 & 0.12 \\
\hline & Specify & 0.01 & 0.01 & 0.04 & $\begin{array}{l}+0.12 \\
\text { NS }\end{array}$ & 16.38* & $\overline{12.57 *}$ & 48 & 0.02 \\
\hline & Addition & 0.15 & 0.21 & 0.18 & $\begin{array}{l}- \\
7.28 * \star\end{array}$ & $\begin{array}{l}+0.93 \\
\text { NS }\end{array}$ & $\begin{array}{l}-1.90 \\
\text { NS }\end{array}$ & 464 & 0.18 \\
\hline & Contrast & 0.08 & 0.05 & 0.07 & $+5.11 *$ & $\begin{array}{l}-1.27 \\
\text { NS }\end{array}$ & $\begin{array}{l}+0.71 \\
\text { NS }\end{array}$ & 161 & 0.06 \\
\hline & Cause-effect & 0.06 & 0.06 & 0.07 & $\begin{array}{l}-0.09 \\
\text { NS }\end{array}$ & $\begin{array}{l}-0.41 \\
N S\end{array}$ & $\begin{array}{l}-0.77 \\
\text { NS }\end{array}$ & 151 & 0.06 \\
\hline & Preface question & 0.04 & 0.03 & 0.02 & $\begin{array}{l}+1.07 \\
\text { NS }\end{array}$ & $\begin{array}{l}+0.56 \\
\text { NS }\end{array}$ & $\begin{array}{l}+2.49 \\
\text { NS }\end{array}$ & 76 & 0.03 \\
\hline & Question token & 0.02 & 0.03 & 0.05 & $\begin{array}{l}-0.29 \\
\mathrm{NS}\end{array}$ & $-4.70 *$ & $-6.38 *$ & 74 & 0.03 \\
\hline \multirow{5}{*}{$\begin{array}{l}\text { Negation } \\
\text { (No) }\end{array}$} & Simple negation & 0.08 & 0.09 & 0.09 & $\begin{array}{l}-0.72 \\
N S\end{array}$ & $\begin{array}{l}-0.06 \\
\text { NS }\end{array}$ & $\begin{array}{l}-0.92 \\
N S\end{array}$ & 214 & 0.08 \\
\hline & Addition & 0.04 & 0.03 & 0.04 & $\begin{array}{l}+1.17 \\
\text { NS }\end{array}$ & $\begin{array}{l}-0.44 \\
\text { NS }\end{array}$ & $\begin{array}{l}+0.04 \\
\text { NS }\end{array}$ & 94 & 0.04 \\
\hline & Correction & 0.01 & 0.02 & 0.03 & $\begin{array}{l}-3.66 \\
N S\end{array}$ & $\begin{array}{l}-0.31 \\
\text { NS }\end{array}$ & $-4.80 *$ & 51 & 0.02 \\
\hline & Disagreement & 0.06 & 0.09 & 0.04 & $-6.38^{\star}$ & $\begin{array}{l}+ \\
13.39 *\end{array}$ & $\begin{array}{l}+2.02 \\
\text { NS }\end{array}$ & 183 & 0.07 \\
\hline & Cause-effect & 0.01 & 0.01 & 0.02 & $\begin{array}{l}-0.14 \\
N S\end{array}$ & $\begin{array}{l}-0.15 \\
N S\end{array}$ & $\begin{array}{l}-0.47 \\
\text { NS }\end{array}$ & 37 & 0.01 \\
\hline
\end{tabular}




\begin{tabular}{|c|c|c|c|c|c|c|c|c|c|}
\hline \multirow[t]{2}{*}{ Word } & \multirow[t]{2}{*}{ Function } & \multicolumn{3}{|c|}{ NF per 100 words } & \multicolumn{3}{|c|}{ Log Likelihood (LL) } & \multicolumn{2}{|c|}{$\begin{array}{l}\text { All PBL } \\
\text { Combined }\end{array}$} \\
\hline & & PBL1 & PBL2 & PBL3 & $\begin{array}{l}\text { PBL1 } \\
\text { versus } \\
2\end{array}$ & $\begin{array}{l}\text { PBL2 } \\
\text { versus } \\
3\end{array}$ & $\begin{array}{l}\text { PBL1 } \\
\text { versus } \\
3\end{array}$ & RF & NF \\
\hline \multirow{2}{*}{$\begin{array}{l}\text { Reactive } \\
\text { (Oh/Ah) }\end{array}$} & Orientation & 0.08 & 0.04 & 0.06 & $\stackrel{+}{10.91 *}$ & $\begin{array}{l}-3.02 \\
\text { NS }\end{array}$ & $\begin{array}{l}+1.31 \\
\text { NS }\end{array}$ & 145 & 0.06 \\
\hline & Recall & 0.04 & 0.01 & 0.02 & $\stackrel{+}{15.15^{\star}}$ & $\begin{array}{l}-0.73 \\
\text { NS }\end{array}$ & $+6.02^{\star}$ & 57 & 0.02 \\
\hline
\end{tabular}

The figures in Table 2 reflect a distinctive feature of PBL 1, namely, that affirmation functions (viz., acknowledgement, confirming, restatement, addition, commenting, contrasting, and question preface) were more prevalent than in either PBL 2 or PBL 3. Moreover, the negation function (viz., addition) and the reactive functions (viz., recall and information orientation) were more frequent in PBL 1 than in PBL 2 or in PBL 3.

However, the addition type of affirmation function was more frequent in PBL 2 ( 0.21 per 100 tokens) than in either PBL 1 ( 0.15 per 100 tokens) or PBL 3 ( 0.18 per 100 tokens). While the addition function was significantly overused in PBL 2, there was no significant difference in its prevalence in PBL 1 and in PBL 3 ( 0.18 vs 0.15 per 100 tokens, $\mathrm{LL}-1.90)$. Although students used approximately 0.1 affirmation words per 100 tokens involving acknowledgement ( 0.11 per 100 tokens), confirming ( 0.12 per 100 tokens), and restating ( 0.10 per 100 tokens) in PBL 2, these figures were significantly less than those recorded in PBL 1 and in PBL 3 (Table 2above). The students used fewer than 0.1 affirmation words per 100 tokens to mark other affirmation functions. In PBL 2, fewer than 0.1 negation words per 100 tokens were used to mark negation functions. However, the prevalence of simple negation ( 0.09 per 100 words) and disagreement ( 0.09 per 100 tokens) functions was close to 0.1 per 100 tokens. While there was no significant variation in the prevalence of the simple negation function across PBL sessions, the disagreement function was significantly more prevalent in PBL 2 (0.09 per 100 tokens) than in PBL 1 ( 0.06 per 100 tokens, $L L+6.38)$ and in PBL 3 (0.04 per 100 tokens, $L L+13.39)$. Similarly, PBL discourse participants used fewer than 0.1 interactional reactive words per 100 tokens to mark the orientation $(0.04$ per 100 tokens) and recall (0.01 per 100 tokens) functions in PBL 2. The prevalence of these functions was significantly less than in PBL 1 ( $0.08 \mathrm{vs}$ 0.04, $L L+10.91 ; 0.04$ vs 0.01, LL + 15.15). The difference between these functions in PBL 2 and in PBL 3 was not significant in relation to the orientation function $(0.06 \mathrm{vs} 0.04, \mathrm{LL}+1.31)$ but significant regarding the recall function (0.02 vs $0.01, L L+6.02)$.

The students used more than 0.1 interactional response words per 100 tokens to mark the acknowledgement ( 0.19 per 100 tokens), agreement ( 0.17 per 100 tokens), confirming ( 0.12 per 100 tokens), and addition ( 0.18 per 100 tokens) functions in PBL 3. However, the frequency of the acknowledgement and confirming functions in PBL 3 was significantly less than in PBL 1 ( $L L+8.50$ and $L L+45.92$, respectively), whereas there was no significant difference in the frequency of the addition function between PBL 1 and PBL 3 (LL - 1.90). PBL 3 was, however, distinctive because, unlike PBL 1 and PBL 2, the students overused affirmation words with the sequence (0.08 per 100 tokens) and specify ( 0.04 per 100 tokens), talk and preface agreement ( 0.17 per 100 tokens), cause-effect ( 0.07 per 100 tokens) and question (0.05 per 100 tokens) functions (Table 2$)$. Furthermore, the students overused negation interactional words to mark the correction ( 0.03 per 100 tokens) and cause-effect ( 0.02 per 100 tokens) 
functions in PBL 3 compared to PBL 1 and PBL 2 (Table 2above). The students used reactive interactional words to mark the idea orientation ( 0.06 per 100 tokens) and recall (0.02 per 100 tokens) functions in PBL 3 . While there was no significant difference in the prevalence of the idea orientation function in PBL 1 and in PBL 3 (0.08 vs 0.06 per 100 words, $L L+1.31$ ), the students significantly overused reaction interactional words to mark the idea recall function in PBL 1 compared to those in PBL 3 (0.04 vs 0.02 per 100 tokens, LL + 6.02).

Generally, the results suggest that the interactional response functions were most frequent in PBL 1, less frequent in PBL 3, and least prevalent in PBL 2.

\section{Evidence of shared understanding Affirmation interactional functions}

The figures in Table 3 (below) show that, overall, more affirmation words ( 0.40 per 100 tokens) were used for interactional responses without content expansion than for interactional responses with complex (0.33 per 100 tokens) and simple (0.29 per 100 tokens) expansions, and least used to mark questions (0.06 per 100 tokens). The interactional responses without content expansion (acknowledgement and continuative) and simple content expansion responses (agree, restate, comment, and confirm) were significantly more frequent in PBL 1 ( 0.58 and 0.34 per 100 tokens, respectively) but less prevalent in PBL 2 ( 0.26 and 0.24 per 100 tokens, respectively). While there was no significant difference in the prevalence of simple content expansion in PBL 1 and in PBL 3, the variation in the prevalence of unexpanded content responses across PBL groups was significant. Interactional responses with complex expansions (addition, contrast, specify, and cause-effect) and questioning responses were more prevalent in PBL 3 (0.36 and 0.07 per 100 tokens, respectively) than in PBL 1 and in PBL 2. While the variation of the questioning function across the PBL sessions was not significant, complex content expansion functions were significantly more prevalent in PBL 3. 
Table 3

Commonly occurring examples of shared understanding: Normalised frequencies per 100 tokens and Log Likelihood values for frequent degrees of interactional responses

\begin{tabular}{|c|c|c|c|c|c|c|c|c|c|}
\hline & & \multicolumn{3}{|c|}{ NF per 100 words } & \multicolumn{3}{|c|}{ Log Likelihood (LL) } & \multicolumn{2}{|c|}{ All groups } \\
\hline & & PBL1 & PBL2 & PBL3 & $\begin{array}{l}\text { PBL1 } \\
\text { versus } \\
2\end{array}$ & $\begin{array}{l}\text { PBL2 } \\
\text { versus } \\
\mathbf{3}\end{array}$ & $\begin{array}{l}\text { PBL1 } \\
\text { versus } \\
3\end{array}$ & RF & NF \\
\hline \multirow[t]{4}{*}{ Affirmation } & $\begin{array}{l}\text { Without content } \\
\text { expansion }\end{array}$ & 0.58 & 0.26 & 0.39 & $\stackrel{+}{119.75^{\star}}$ & $-\overline{19.06 *}$ & $\stackrel{+}{25.66^{*}}$ & 1015 & 0.40 \\
\hline & $\begin{array}{l}\text { With simple content } \\
\text { expansion }\end{array}$ & 0.34 & 0.24 & 0.32 & $\begin{array}{l}+ \\
20.06 *\end{array}$ & $-\overline{9} .58 *$ & $\begin{array}{l}+0.32 \\
\text { NS }\end{array}$ & 739 & 0.29 \\
\hline & $\begin{array}{l}\text { With complex content } \\
\text { expansion }\end{array}$ & 0.30 & 0.33 & 0.36 & $\begin{array}{l}-1.19 \\
\text { NS }\end{array}$ & $\begin{array}{l}-1.15 \\
\text { NS }\end{array}$ & $-8.84 *$ & 824 & 0.33 \\
\hline & Mark question & 0.06 & 0.05 & 0.07 & $\begin{array}{l}+0.19 \\
\text { NS }\end{array}$ & $\begin{array}{l}-1.32 \\
\text { NS }\end{array}$ & $\begin{array}{l}-0.53 \\
\text { NS }\end{array}$ & 150 & 0.06 \\
\hline \multirow[t]{2}{*}{ Negation } & $\begin{array}{l}\text { Without content } \\
\text { expansion }\end{array}$ & 0.08 & 0.09 & 0.09 & $\begin{array}{l}-0.72 \\
\text { NS }\end{array}$ & $\begin{array}{l}-0.06 \\
\text { NS }\end{array}$ & $\begin{array}{l}-0.92 \\
\text { NS }\end{array}$ & 214 & 0.08 \\
\hline & $\begin{array}{l}\text { With complex content } \\
\text { expansion }\end{array}$ & 0.13 & 0.16 & 0.13 & $-4.31 *$ & $\begin{array}{l}+3.23 \\
\text { NS }\end{array}$ & $\begin{array}{l}-0.00 \\
\text { NS }\end{array}$ & 365 & 0.14 \\
\hline \multirow[t]{2}{*}{ Reactive } & $\begin{array}{l}\text { Without content } \\
\text { expansion }\end{array}$ & 0.08 & 0.04 & 0.06 & $\begin{array}{l}+ \\
10.91 *\end{array}$ & $\begin{array}{l}-3.02 \\
\text { NS }\end{array}$ & $\begin{array}{l}+1.31 \\
\text { NS }\end{array}$ & 145 & 0.08 \\
\hline & $\begin{array}{l}\text { With simple content } \\
\text { expansion }\end{array}$ & 0.04 & 0.01 & 0.02 & $+{ }^{+} 15.15^{\star}$ & $\begin{array}{l}-0.73 \\
N S\end{array}$ & $\begin{array}{l}+ \\
6.02 *\end{array}$ & 57 & 0.04 \\
\hline
\end{tabular}

\section{Negation interactional functions}

Generally, negation words were more frequently used for complex content expansion functions (0.14 per 100 tokens) than for unexpanded content functions (0.08 per 100 tokens). Unexpanded content (simple negation) functions had equal prevalence in PBL 2 (0.09 per 100 tokens) and in PBL 3 (0.09 per 100 tokens), but slightly less in PBL 1 (0.08 per 100 tokens). However, there was no significant difference in the variation of unexpanded functions across the PBL sessions. The complex content expansion functions (viz., addition, contradiction, and correction) were significantly more prevalent in PBL 2 (0.16 per 100 tokens) than in either PBL 1 (0.13 per 100 tokens) or PBL 3 (0.13 per 100 tokens).

\section{Reaction interactional functions}

Reaction interactional words were used predominantly for unexpanded functions (0.08 per 100 tokens) rather than for simple content expansion functions (0.04 per 100 tokens). Both these reaction interactional functions were frequent in PBL 1 (0.08 and 0.04 per 100 tokens, respectively), less prevalent in PBL 3 (0.06 and 0.02 per 100 tokens, respectively), and occurred least in PBL 2 (0.04 and 0.01 per 100 tokens, respectively). The unexpanded function was significantly more prevalent in PBL 1 than in PBL 2 (LL + 10.91), but there was no significant prevalence difference between PBL 1 and PBL $3(L L+1.31)$. The simple content expansion function was significantly more prevalent in PBL 1 than in PBL $2(L L+15.15)$ or PBL $3(L L+6.02)$. 


\section{Discourse content}

Generally, students used 1.5 interactional response words to mark knowledge discourse, about 1.0 interactional response words to preface task planning, and fewer than 1.0 interactional response words to mark physical action, humour, and reflection discourse (Table 4 below). Moreover, while there was no significant difference in the overall frequency of the interactional discourse contents in PBL 1 and in PBL 3 (1.92 vs 1.79 per 100 tokens, LL + 3.12), the interactional discourse contents were less prevalent in PBL 2 when compared to PBL 1 (1.40 vs 1.92, LL - 78. 83) and PBL 3 (1.40 vs 1.79, LL - 36.56). The data in Table 4 show that students generally used more than 1.0 interactional response words to mark knowledge discourse across the tutorial sessions. Knowledge discourse had the highest prevalence in PBL 3 (1.65 per 100 tokens), but there was no difference in the prevalence of knowledge discourse marked with interactional response words in PBL 1 and in PBL 3 (1.57 vs 1.65 per 100 tokens, LL 1.43), implying that knowledge discourse was the least prefaced with interactional response words in PBL 2. Interactional response words were significantly overused to mark task planning discourse in PBL 1 (0.21 per 100 tokens), whereas task planning discourse had an equal frequency in PBL 2 and in PBL 3 (0.003 per 100 tokens each, LL - 0.63). Physical activity discourse marked with interactional response words varied significantly across tutorial sessions, but they were most prevalent in PBL 1 ( 0.11 per 100 tokens) and least frequent in PBL 2 (0.01 per 100 tokens). Further, interpersonal humour marked with interactional response words was most prevalent in PBL 1 (0.02 per 100 tokens), whereas reflection marked with interactional response words was limited to PBL 3 .

Table 4: Discourse content: Raw and normalised frequency per 100 tokens and the Log Likelihood value for the commonly occurring discourse content in each problem-based learning session

\begin{tabular}{|c|c|c|c|c|c|c|c|c|c|c|c|}
\hline \multirow[t]{3}{*}{ Content } & \multicolumn{6}{|c|}{ PBL session } & \multicolumn{3}{|c|}{ Log Likelihood (LL) } & \multirow{2}{*}{\multicolumn{2}{|c|}{$\begin{array}{l}\text { All PBL } \\
\text { sessions } \\
\text { combined }\end{array}$}} \\
\hline & \multicolumn{2}{|l|}{ PBL 1} & \multicolumn{2}{|l|}{ PBL 2} & \multicolumn{2}{|l|}{ PBL 3} & \multirow{2}{*}{$\begin{array}{l}\text { PBL1 } \\
\text { versus } \\
2\end{array}$} & \multirow{2}{*}{$\begin{array}{l}\text { PBL2 } \\
\text { versus } \\
3\end{array}$} & \multirow{2}{*}{$\begin{array}{l}\text { PBL1 } \\
\text { versus } \\
3\end{array}$} & & \\
\hline & RF & NF & RF & NF & RF & NF & & & & RF & NF \\
\hline Knowledge & 1358 & 1.57 & 1474 & 1.36 & 960 & 1.65 & + & $-\overline{22.36 *}$ & $-\overline{1.43 N S}$ & 3792 & 1.50 \\
\hline $\begin{array}{l}\text { Task } \\
\text { planning }\end{array}$ & 184 & 0.21 & 28 & 0.03 & 19 & 0.03 & $\begin{array}{l}+ \\
166.90^{*}\end{array}$ & $\begin{array}{l}-0.63 \\
N S\end{array}$ & $\stackrel{+}{97.63^{*}}$ & 231 & 0.09 \\
\hline $\begin{array}{l}\text { Physical } \\
\text { action }\end{array}$ & 99 & 0.11 & 9 & 0.01 & 14 & 0.02 & $\stackrel{+}{109.79 *}$ & $-6.45^{\star}$ & $\stackrel{+}{42.64^{\star}}$ & 122 & 0.05 \\
\hline $\begin{array}{l}\text { Interpersonal } \\
\text { humour }\end{array}$ & 15 & 0.02 & 8 & 0.01 & 1 & 0.00 & $+4.07^{\star}$ & $\begin{array}{l}+2.68 \\
\text { NS }\end{array}$ & $+9.76^{*}$ & 24 & 0.01 \\
\hline Reflection & 0 & 0.00 & 0 & 0.00 & 44 & 0.08 & $\begin{array}{l}+0.00 \\
\text { NS }\end{array}$ & 92.81* & $-80.21 *$ & 44 & 0.02 \\
\hline Total & 1656 & 1.92 & 1519 & 1.40 & 1038 & 1.79 & $+\frac{+}{78.83^{*}}$ & $-\overline{36.56 *}$ & $\begin{array}{l}+3.12 \\
\text { NS }\end{array}$ & 4213 & 1.66 \\
\hline
\end{tabular}

\section{Discussion}


In this study, we applied corpus linguistic methodology to explore graduate entry medical students' shared understanding in medical PBL tutorial conversations.

The interactional response words indicating shared understanding showed certain noteworthy features. The low prevalence of non-lexical 'oh/ah' response words, overall and in each PBL session, suggests that the students engaged in active interactive conversations, as one would expect in a PBL situation, and invested more in collaborative efforts, with less emphasis on non-vocal reactions. Shared understanding is attained through a collaborative process that requires effort from discourse participants $[22,23]$. The affirmation interactional response words contained a mixture of 'yeah' and 'yes' words. The prevalence of 'yeah' interactional response words could suggest that the students pronounced the lexical form 'yes' informally, which supports the likelihood of a more relaxed collegial discourse within participants' interactive responses that generally characterises a tutorled classroom.

In general, data analysis results suggest that interactional response words were most frequent in PBL 1 , and least prevalent in PBL 2. This finding suggests that most interactional-response-word-prefaced conversation may have occurred in PBL 1, perhaps meaning that the students were engaged in trying to understand what was required and the perspectives involved concerning the new case problem. The participants in this study were mature learners with rich educational, work, and life experiences that they could bring to bear collectively. Any ensuing conflicts, which perhaps needed resolving to attain a shared understanding, may have resulted in the overuse of interactional response words to preface their discourse. Moreover, the low prevalence of interactional response words in PBL 2 seems reasonable; the students might have resolved conflicts due to contrasting understandings in PBL 1, and PBL 2 could have been devoted to long stretches of discourse as they presented the results of their self-directed learning. The prevalence of interactional response words in PBL 3 followed the PBL 1 pattern. This finding suggests that the students marked their discourse with interactional response words as they negotiated the pros and cons of management plans and expressed individual views about the case scenario, their input, and how the PBL cycle had been conducted.

Shared meaning in interactive talk progresses and accumulates incrementally through processes of refinement and monitoring $[10,24]$. The various affirmation interactional response functions in this study suggest that the students appear to have engaged in interactional responses in which they agreed explicitly with peers' contributions, checked and monitored mutual understanding, as well as confirmed, reasserted, repaired, and expanded peers' ideas and information to achieve shared meaning. The prevalence of negation interactional response functions, overall and across the PBL sessions, suggests that the students engaged in discussions involving contending views in relation to their knowledge and ideas, and provided sophisticated evidence for their disagreements in the form of corrections, additions, and cause-effect relationships. Reactive interactional response words were used to orientate students to peers' contributions and recall previous knowledge and ideas. Orientation to information and information recall are considered to be associated with the creation of shared knowledge [25].

Further analysis of interactional response words provided various levels of evidence to show how the students shared an understanding in their tutorial conversation. Affirmation interactional response words were used for a mixture of unexpanded and simple and complex content expansion talk. Although interactional response functions without content expansion, such as acknowledgement and talk sequence (in instalments and continuatively) may constitute lower-order evidence of shared meaning, they are essential in that they indicate the attention and mutual support that students give to each other during talk-in-interaction [26]. These functions were 
more prevalent in PBL 1, where the focus was on hypothesis generation with limited criticism, than in other PBL sessions. Interactional response functions with content expansion could be simple or complex. Simple content expansion provided more developed evidence of shared meaning through confirming, restatement, paraphrasing, and comment on ideas and perspectives. More sophisticated and complex forms of content expansion were also evident in the students' conversation, as the students extended the contribution of a prior speaker through the addition of further information, contrasting of ideas, the development of specificity through refining previous contributions, and cause-effect enhancement [10]. This process of shared understanding aligned with integrationoriented consensus building as described by Weinberger and Fischer [27].

Conflict is a potent stimulus for knowledge development and attainment of shared understanding, in that it can generate explanation, justification, and reflection [26]. While students engaged in simple negation responses in all tutorial groups in this study, they were also involved in content expansion conflict-oriented talk. There was disagreement about ideas and correction of perspectives with the potential for conceptual change and shared meaning. This finding suggests the presence of conflict-oriented consensus building talk [27] in the tutorial groups, primarily in PBL 2. Overall, disagreement functions were more prevalent in PBL 2, and this finding concurs with the focus of the session, where students were expected to challenge each other's ideas and critically scrutinise the credibility and sources of the knowledge emanating from self-study.

The presence of reactive interactional response information orientation and recall functions is also noteworthy. Heritage [28] and Goffman [29] have observed that information orientation and recall evoked by peers' contributions lead to understanding convergence through aligning a listener's understanding with that of the speaker. Schiffrin [25] also observed that orientation to information and information recall are associated with shared knowledge.

The interactional processes in this study were mainly knowledge-based. Physical action and task coordination were more prevalent in PBL 1 than in either PBL 2 or PBL 3. This finding was expected, because the students planned tasks and engaged in writing on the blackboard in PBL 1. It is also not surprising that interactional response words were used to mark reflection talk in PBL 3, since this type of discourse activity was confined to this session.

\section{Conclusion}

This study was process-focused, conducted in a natural educational setting, used a systematic corpus analysis methodology to analyse transcripts involving full cycles of eight PBL tutorial groups, and explored a fundamental concept of PBL, namely, shared understanding. Moreover, through the methodology, we were able to detect statistically significant differences in relative frequencies between PBL sessions, thus enabling us to relate the differences to the learning focus of the sessions.

However, the study has some limitations. First, shared understanding lies in the minds of discourse participants. Since it is impossible to examine human minds directly to establish whether an understanding is shared, discourse content has been used as a surrogate for this. The discourse participants in this study may have used discourse tokens of shared understanding as face-saving tactics without necessarily agreeing with peers. Second, the results of the study may not be readily generalisable to other institutions, since PBL transcripts from only one institution have been analysed. Third, the results of the study may also not be generalised to an undergraduate PBL curriculum, as the study participants were graduate students. However, the goal of the study was to enable 
generalisability in relation to PBL theory and not regarding the participants [30]. Fourth, participation in this study was voluntary. It is impossible to know whether students who did not participate had a similar pattern of shared understanding in the tutorial discourse. Fifth, we only investigated frequent small interactional response words as indicators of shared understanding. Shared understanding could be attained through many other linguistic tokens $[20,31]$ that were not investigated in this study. Shared understanding could also be achieved through nonverbal gestures. However, analysis of nonverbal gestures was not the focus of this research. Finally, the reliability of coding of interactional response word functions has not been assessed in this study for practical reasons, although other researchers have applied a similar procedure to the corpus analysis methodology [32, 33].

Many questions remain to be answered in future research. More work is needed to explore how other linguistic tokens and nonverbal gestures are used to achieve shared meaning in PBL tutorial discourse. Future research could also explore the effect of group composition on the evidence levels of shared understanding.

The findings of this study have numerous theoretical and practical implications. Theoretically, this study explored shared understanding as an essential PBL concept, and practically, it provided insight into how medical students' shared understanding developed at different phases of the PBL cycle by describing and analysing linguistic tokens of shared understanding.

This study showed that the extent of verbalisation influences the quality of shared understanding. The interactional response tokens enriched with expanded content provided sophisticated evidence of shared understanding compared to unexpanded tokens. Practically, suggestions that are relevant to educational practice could be derived from this finding. Facilitators need to encourage students to expand their interactional responses and urge quieter students to verbalise their ideas. Medical educators also need to train students on how to communicate with understanding as this is very important for interprofessional practice and effective patientdoctor decision-making process.

\section{Abbreviations}

PBL Problem-Based Learning

OMT Olukayode Matthew Tokode

RD Reg Dennick

NF Normalised frequency

RF Raw frequency

LL Log Likelihood

NS Not significant

\section{Declarations}

Ethics approval and consent to participate: The study was approved by the University of Nottingham Ethics Committee - Ethics approval for the study is $D / 9 / 2008$. The study participants signed an informed consent to participate in the study. 
Consent for publication: The authors have reviewed the manuscript and agree on its content for publication.

Availability of data and material: The anonymised data that support the findings of this study are available from the authors upon request.

Competing interests: The authors report no declarations of interest.

Funding: No funding was received for this project.

Authors' contributions: RD initiated the project; OMT collected and processed the data. Both authors drafted the paper and approved the final version for publication.

Acknowledgements: We acknowledge the assistance of the students and staff of the University of Nottingham Medical School in Derby.

\section{References}

1. Svinicki MD: Moving beyond "it worked": The ongoing evolution of research on problem-based learning in medical education. Educ Psychol Rev 2007, 19(1):49-61.

2. Hurk MM, Dolmans DHJM, Wolfhagen IHAP, Vleuten CPM: Quality of student-generated learning issues in a problem-based curriculum. Med Teach 2001, 23(6):567-71.

3. Hmelo-Silver CE, Barrows HS: Facilitating collaborative knowledge building. Cognition and Instruction 2008, 26(1):48-94.

4. Imafuku R, Kataoka R, Mayahara M, Suzuki H, Saiki T: Students' experiences in interdisciplinary problembased learning: A discourse analysis of group interaction. Interdisciplinary Journal of Problem-Based Learning 2014, 8(2):1-18.

5. Diemers AD, van de Wiel MWJ, Scherpbier AJJA, Baarveld F, Dolmans DHJM: Diagnostic reasoning and underlying knowledge of students with preclinical patient contacts in PBL. Med Educ 2015, 49(12):1229-38.

6. De Grave WS, Boshuizen HPA, Schmidt HG: Problem based learning: Cognitive and metacognitive processes during problem analysis. Instructional Science 1996, 24(5):321-41.

7. De Grave WS, Schmidt HG, Boshuizen HPA: Effects of problem-based discussion on studying a subsequent text: A randomized trial among first year medical students. Instructional Science 2001, 29(1):33-44.

8. Yew EHJ, Schmidt HG: Evidence for constructive, self-regulatory, and collaborative processes in problembased learning. Advances in Health Sciences Education 2009, 14(2):251-73.

9. Stahl G: A model of collaborative knowledge-building. In: Fourth international conference of the learning sciences: 2000; Mahwah, NJ: Erlbaum; 2000: 70-77.

10. Roschelle J: Learning by collaborating: Convergent conceptual change. Journal of the Learning Sciences 1992, 2(3):235-76.

11. Koschmann T, MacWhinney B: Opening the black box: Why we need a PBL TalkBank database. Teach Learn Med 2001, 13(3):145-47.

12. Da Silva AL, Dennick R: Corpus analysis of problem-based learning transcripts: an exploratory study. Med Educ 2010, 44(3):280-88. 
13. Vygotsky LS: Mind in society: The development of higher psychological processes Massachusetts: Harvard University Press; 1978.

14. Mulder I, Swaak J, Kessels J: Assessing group learning and shared understanding in technology-mediated interaction. Journal of Educational Technology \& Society 2002, 5(1):35-47.

15. Schegloff EA: Conversation analysis and socially shared cognition. In: Perspectives on socially shared cognition. edn. Edited by Resnick LB, Levine JM, Teasley SD. https://doi.org/10.1037/10096-007: American Psychological Association; 1991: 150-71.

16. Oliveira AW, Sadler TD: Interactive patterns and conceptual convergence during student collaborations in science. Journal of Research in Science Teaching 2008, 45(5):634-58.

17. Vyt A: Interprofessional and transdisciplinary teamwork in health care. Diabetes Metab Res Rev 2008, 24(S1):S106-S09.

18. Teutsch C: Patient-doctor communication. Medical Clinics 2003, 87(5):1115-45.

19. Gilbert J, Camp II R, Cole C, Bruce C, Fielding D, Stanton S: Preparing students for interprofessional teamwork in health care. Journal of Interprofessional care 2000, 14(3):223-35.

20. McCarthy M: Talking back:" Small" interactional response tokens in everyday conversation. Research on Language and Social Interaction 2003, 36(1):33-63.

21. Hsieh HF, Shannon SE: Three approaches to qualitative content analysis. Qual Health Res 2005, 15(9):127788.

22. Baker M, Hansen T, Joiner R, Traum D: The role of grounding in collaborative learning tasks. In: Collaborative learning: Cognitive and computational approaches. edn. Edited by Dillenbourg P. Oxford: Elsevier Sciences Ltd.; 1999: 31-63.

23. Clark HH, Wilkes-Gibbs D: Referring as a collaborative process. Cognition 1986, 22(1):1-39.

24. Sacks H, Schegloff EA, Jefferson G: A simplest systematics for the organization of turn taking for conversation. Language 1974, 50: 696-735. http://dx.doi.org/10.2307/412243.

25. Schiffrin D: Discourse markers. Cambridge: University Press; 1987.

26. Van Boxtel C, Van der Linden J, Kanselaar G: Collaborative learning tasks and the elaboration of conceptual knowledge. Learning and Instruction 2000, 10(4):311-30.

27. Weinberger A, Fischer F: A framework to analyze argumentative knowledge construction in computersupported collaborative learning. Computers \& Education 2006, 46(1):71-95.

28. Heritage J: "A change-of-state token and aspects of its sequential placement ". In: In Structures of social action: studies in conversation analysis. edn. Edited by Atkinson JM, Heritage J. Cambridge, London, New York, New Rochelle, Melbourne, Sydney: Cambridge University Press; 1984: 299-345.

29. Goffman E: Forms of talk. Philadelphia, Pennsylvania 19104-4011: University of Pennsylvania Press; 1981.

30. Yin RK: Case Study Research and Applications: Design and Methods, 6th edn. Califonia, London, New Delhi and Singapore: SAGE Publications, Inc; 2018.

31. Duncan Jr S, Niederehe G: On signalling that it's your turn to speak. J Exp Soc Psychol 1974, 10(3):234-47.

32. Carbonell-Olivares M: A corpus-based analysis of the meaning and function of although. International Journal of English Studies 2009, 9(3):191-208.

33. Demmen J, Semino E, Demjén Z, Koller V, Hardie A, Rayson P, Payne S: A computer-assisted study of the use of violence metaphors for cancer and end of life by patients, family carers and health professionals. 
International Journal of Corpus Linguistics 2015, 20(2):205-31. 